\title{
Physiotherapy in elderly with severe spinal cord injury non-operative due to osteoporosis: case report
}

\author{
João Simão de Melo Neto',2,3, Fabiana de Campos Gomes ${ }^{3}$
}

\begin{abstract}
Introduction: Fall is one the main causes of spinal cord injury ( $\mathrm{SCl}$ ) in the elderly and is associated with an increased number of complications. Thus, studies on this subject are of extreme importance and need for there to be progress and improvements in the rehabilitation process. Objective: Report the case of woman, 62 years old, with osteoporosis and multiple vertebral fractures in the spine, after a fall to the ground. Method: We report a case of woman, 62 years old, with osteoporosis and multiple vertebral fractures in the spine, after a fall to the ground. The Patient was admitted with a chief complaint of severe pain in the lumbar and thoracic regions, and started physical therapy distributed three times per week (10 sessions of 45 minutes/session), with period of 48 hour interval between sessions. During all sessions the Numerical Rating Scale (NRS) was used for pain measurement. Patient was submitted to assessment of fear of falling by scale Falls Efficacy Scale - International - Brazil, and quality of life using questionnaire Short Form (36) Health Survey (SF-36). Results: The patient began treatment with intense pain, but after the third session the pain ceased and remained absent until the end of treatment. Regarding the fear of falling, there was a significant reduction in the level of concern. When initiating treatment, the patient showed impaired quality of life, but after physical therapy there was significant improvement. Conclusion: The physiotherapy promoted reduction of pain, fear of falling and improved the quality of life of patient with spinal cord trauma.
\end{abstract}

Keywords: Spine trauma; Physical Therapy Specialty; Fear; Quality of Life; Pain.

\section{INTRODUTION}

Fall is one the main causes of spinal cord injury $(\mathrm{SCl})$ in the elderly and is associated with an increased number of complications..$^{(1-3)} \mathrm{SCl}$ are spinal injuries associated with motor, sensory and autonomic deficits, and these may be irreversible. $(4,5)$ There are few studies that analyze the applicability of Physiotherapy in individuals who suffered $\mathrm{SCl}$, thus, studies are of extreme importance and need for there to be progress and improvements in the rehabilitation process.

The aim of this study is report the case of a patient with spinal cord injury submitted to physiotherapy treatment with relation to pain symptoms, fear of falling and quality of life.

\section{METHOD}

Report the case of woman, 62-year-old, civil servant removed from office (housekeeping), diagnosed with osteoporosis, hypothyroidism and multiple level spine fractures, after a fall to the ground. The patient received all the information relating to studying and signed the informed consent.

Magnetic resonance imaging in detecting fractures of the vertebral bodies T8, T9, T10, T12 e L1; mild retropulsion of the bone fragments of the vertebral body of T12 determining the compression on the dural sac; anterior and lateral marginal osteophytes in vertebral bodies in the thoracic and lumbar

Corresponding author: João Simão de Melo Neto. Street José Picerni, 660. Jd. Panorama, São José do Rio Preto (SP), Brazil. E-mail: joaosimao03@hotmail.com

${ }^{1}$ Curso de Medicina, Faculdade CERES (FACERES), São José do Rio Preto (SP), Brazil.

2 Instituto Municipal de Ensino Superior de Catanduva (IMES- Catanduva), Catanduva (SP), Brazil.

${ }^{3}$ Faculdade de Medicina de São José do Rio Preto (FAMERP), São José do Rio Preto (SP), Brazil.

Financial support: There was no source of support. 
segments; lumbar and thoracic invertebral discs dehydration (Figure 1).

The Patient was admitted with a chief complaint of severe pain in the lumbar and thoracic regions, presented scale ASIA "E" and no neurological deficit. Physical therapy was distributed in three times per week (10 sessions of 45 minutes/session), with period of one day interval between sessions. The interventions applied were performed manual therapy techniques, exercise for spinal segmental stabilization and functional exercises.

During all sessions the Numerical Rating Scale (NRS) was used for pain measurement, where 0 (zero) represents no pain and 10 (ten) extreme pain. ${ }^{(6-8)}$

Patient was submitted to assessment of fear of falling ${ }^{(9-1)}$ and quality of life ${ }^{(12,13)}$ scale in three stages, before the initiation of treatment, after the fifth session and after the tenth session (Sample 1, 2 and 3, respectively). Fear of falling was assessment for Falls Efficacy Scale - International - Brazilian (FES-I-Brazil). ${ }^{(9-11)}$
To analyze the health-related quality of life was used generic questionnaire Short Form (36) Health Survey (SF-36). ${ }^{(12,13)}$

The Kolmogorov-Smirnov test was used to verify normality of data. Normal Data was available for repeated measures analysis of variance (ANOVA) using post-test Tukey-Kramer and data with non-normal distribution we used the Friedman test and Dunn's post-test. All analyzes were performed with Instat (version 3.0, GraphPad, Inc., San Diego, CA, USA).

\section{RESULTS}

The pain reported by the patient obtained by NRS is shown in Figure 1. The patient began treatment with intense states of pain $(N R S=9)$, however after the third session $(N R S=0)$ the pain ceased and remained absent until the end of treatment (Figure 2).

Regarding the assessment of fear of falling, there was a significant reduction in the level of concern (Figure 3), especially in relation to certain functions (Figure 4).
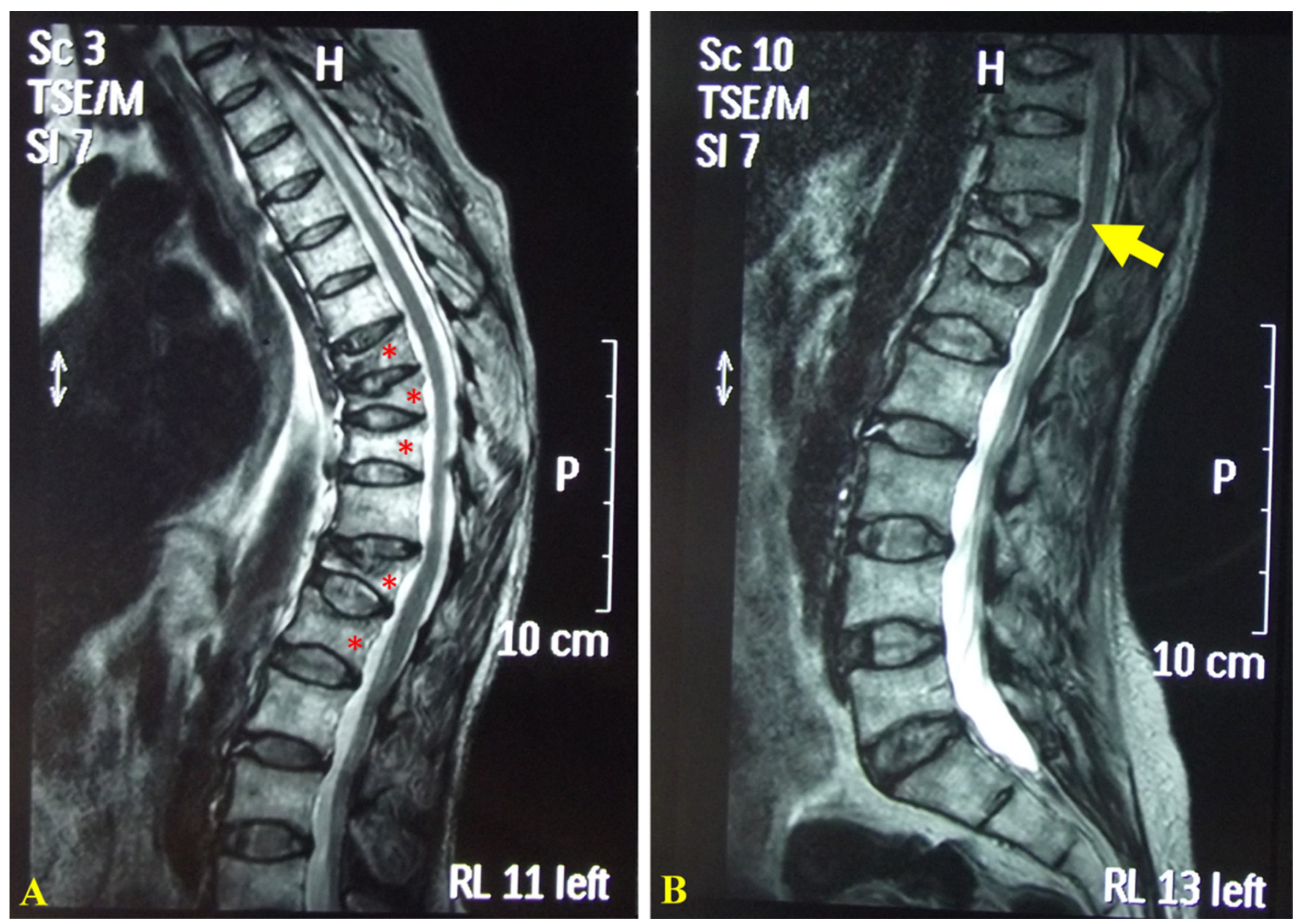

Figure 1. Magnetic resonance imaging of the thoracic spine $(\mathrm{A})$ and lumbar $(\mathrm{B}) .\left(^{*}\right)$ - Fractures of the vertebral bodies; (Arrow) - Mild retropulsion of the bone fragment of the vertebral body of T12. 
Using the SF-36, we observed that initially the patient presented lower quality of life and that there was an improvement after the fifth session and the end of treatment (Figure 5). The domains that had worse quality of life in the initial assessment were functional capacity; limitations due to physical aspects and emotional aspects. All domains showed improvement in quality of life compared to Sample 1 (Figure 6).

\section{DISCUSSION}

The region of thoracolumbar transition is more susceptible to injury because it is an area of transition from a fixed segment (rib cage) and an area with greater mobility (lumbar spine), thus, may result in movements above the physiological limit and consequently in injury. ${ }^{(14,15)}$

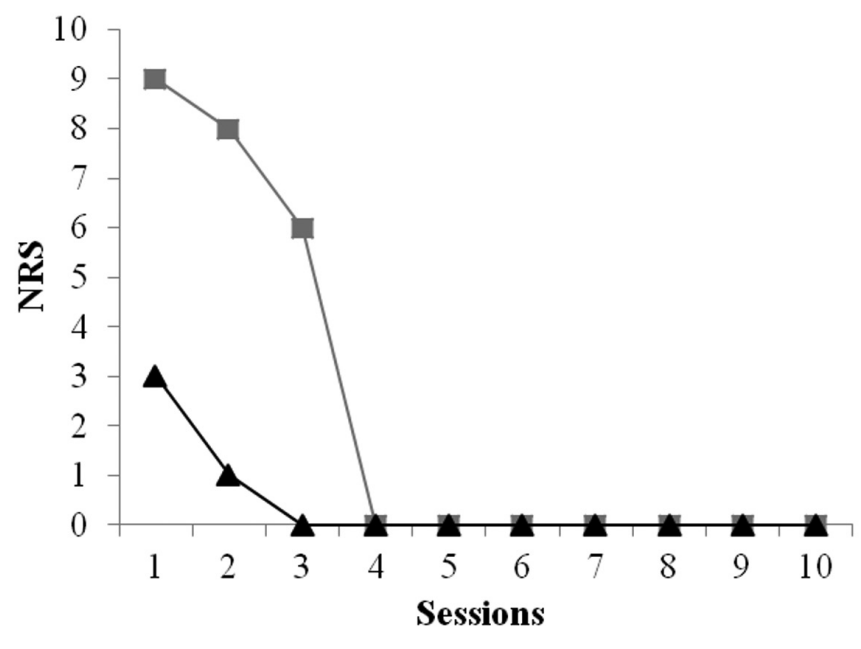

\section{Before the Sessions $\rightarrow-$ After the Sessions}

Figure 2. Pain intensity during treatment through the Numerical Rating Scale (NRS) for pain.

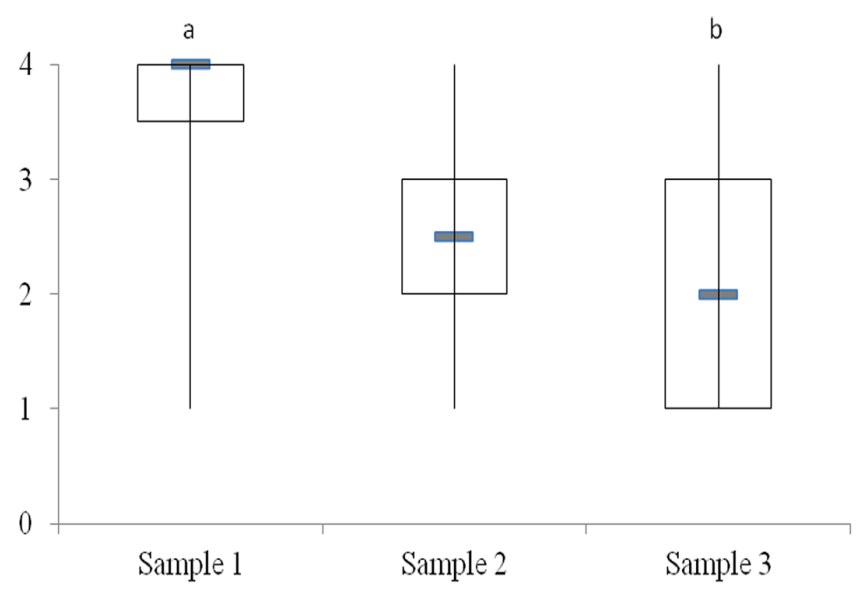

Figure 3. Fear of falling, before (Sample 1), after five sessions (Sample 2) and the end of treatment (Sample 3), obtained of FES-I-Brazil. Friedman test $p=0.003$. ${ }^{a, b} p<0.05$, Dunn's post-test.
The patient showed absent pain after the treatment. The manual therapy has been effective, but the mechanisms of clinical efficacy are not established. Bialosky et al. ${ }^{(16)}$ have proposed that mechanical stimuli promote a cascade of neurophysiological events in the peripheral and central nervous system.

After a fall, there is an increased fear due to concerns and panics regarding the possible consequences of the fall,(17) as observed in this study. The rehabilitation promotes increased locomotors function in these patients, ${ }^{(18)}$ thus resulting in less fear of falling, committing fewer activities of daily living and increasing quality of life, confirming our results. The mechanisms of physiotherapy need to be further studied to increase investments and adaptations in the rehabilitation process. ${ }^{(18)}$

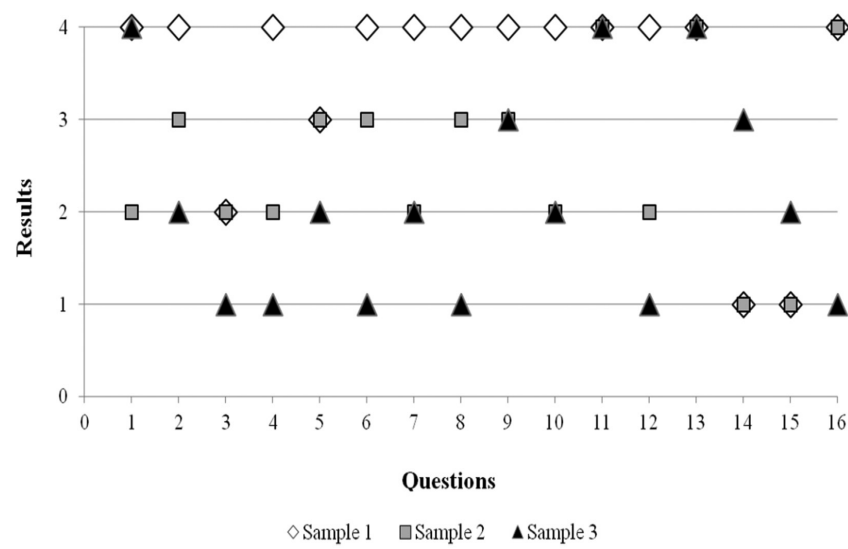

Figure 4. Data on questions related to fear of falling, before (Sample 1), after five sessions (Sample 2) and the end of treatment (Sample 3), obtained by the FES-I-Brazil.

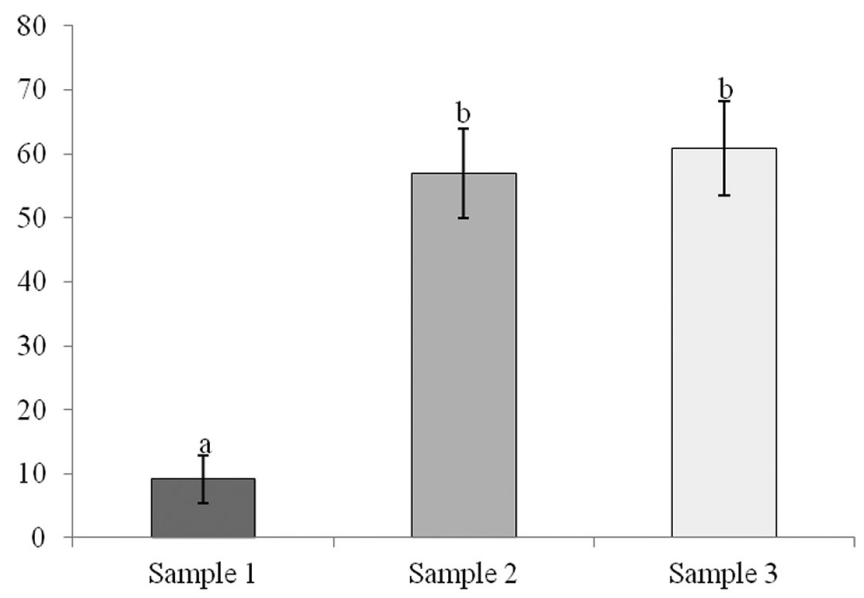

Figure 5. Quality of life health-related before (Sample 1), after five sessions (Sample 2), and the end of treatment (Sample 3) by means of the SF-36. Repeated measures ANOVA, $p<0.0001 .{ }^{a, b} p<0.05$, Tukey-Kramer post-test. 


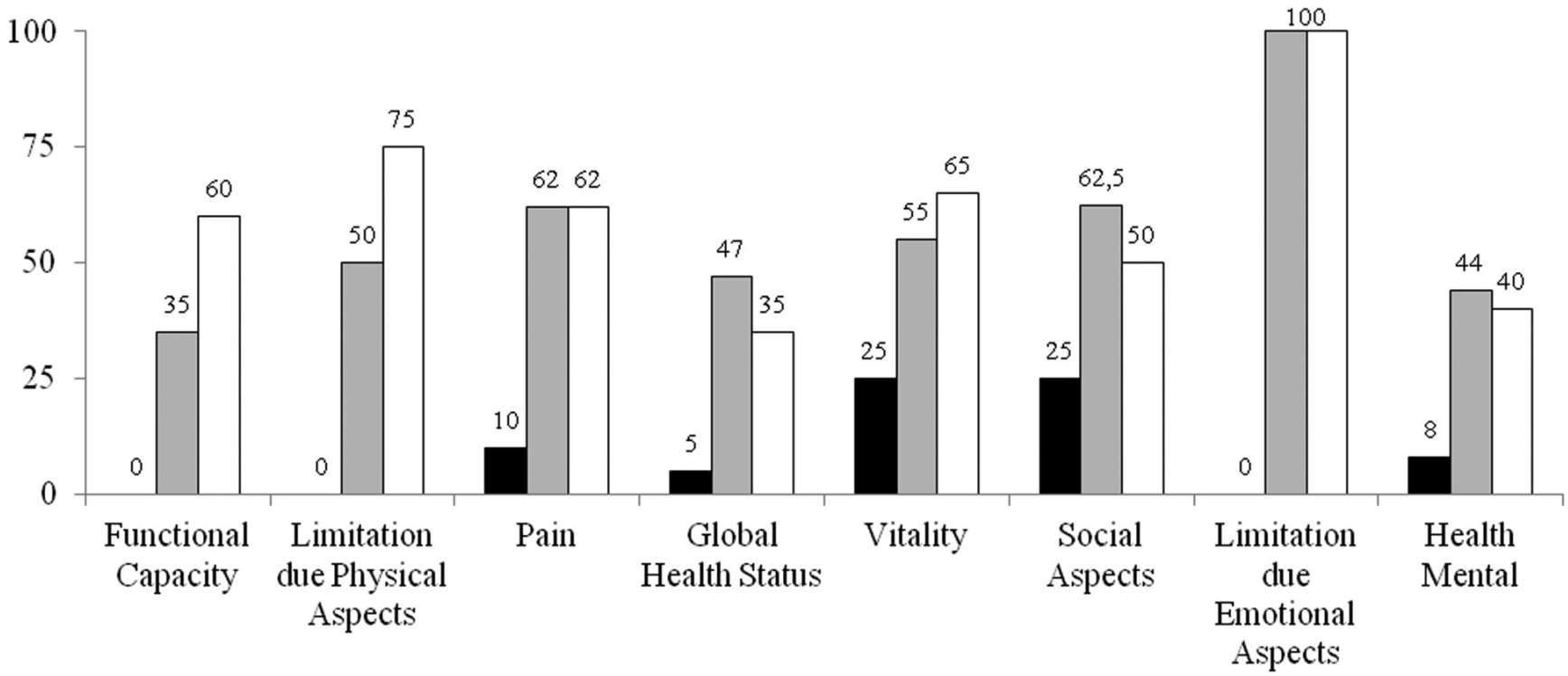

ロ Sample $1 \quad \square$ Sample $2 \quad \square$ Sample 3

Figure 6. Domains of quality of life before (Sample 1), after five sessions (Sample 2) and after the treatment (Sample 3).

\section{CONCLUSION}

In this patient, we concluded that physiotherapy promoted reduction of pain, fear of falling and improved the quality of life of patients with spinal cord trauma.

\section{AUTHORS CONTRIBUTION}

All authors performed the design and planning of the research project, collecting, analyzing and interpreting data, writing, read and approved the final manuscript.

\section{CONFLICT OF INTEREST}

There was no conflict of interest.

\section{REFERENCES}

1. Anderle DV, Joaquim AF, Soares MS, Miura FK, Silva FL, Veiga JCE, et al. Epidemiological evaluation of patients with spinal cord injury treated surgicall on the hospital "Professor Carlos da Silva Lacaz". Coluna/ Columna. 2010;9(1):58-61.

2. Morais DF, Spotti AR, Cohen MI, Mussi SE, Melo Neto JS, Tognola WA. Perfil epidemiológico de pacientes com traumatismo raquimedular atendidos em hospital terciário. Coluna/Columna. 2013;12(2):149-52.

3. Morais DF, Melo Neto JS de, Spotti AR, Tognola WA. Predictors of clinical complications in patients with spinomedullary injury. Coluna/Columna. 2014;13(2):139-42.

4. Morais DF, Melo Neto JS de, Meguins LC, Mussi SE, Ferraz Filho JRL, Tognola WA. Clinical applicability of magnetic resonance imaging in acute spinal cord trauma. Eur Spine J. 2014;23:1457-63.

5. Melo Neto JS de, Tognola WA, Spotti AR, Morais DF. Analysis of patients with spinal cord trauma associated with traumatic brain injury. Coluna/ Columna. 2014;13(4):302-5.

6. Herr KA, Mobily T, Kohout FJ, Wagenaar D. Evaluation of the faces pain scale for use with elderly. Clin J Pain. 1998;14:29-38.

7. Ferrell BA. Pain Management. Clin Geriatr Med. 2000;16(4):853-74.
8. Andrade FA, Pereira LV, Souza FAEF. Mensuração da dor no idoso: uma revisão. Rev. Latino-Am. Enfermagem. 2006;14(2):271-6.

9. Tinetti ME, Richman D, Powell L. Falls efficacy as a measure of fear of falling. J Gerontol. 1990;45(6):239-43.

10. Yardley L, Beyer N, Hauer K, Kempen G, Piot-Ziegler C, Todd C. Development and initial validation of the Falls Efficacy Scale-International (FES-I). Age Ageing. 2005;34(6):614-9.

11. Camargos FFO, Dias RC, Dias JMD, Freire MTF. Cross-cultural adaptation and evaluation of the psychometric properties of the Falls Efficacy Scale - International Among Elderly Brazilians (FES-I-BRAZIL). Rev. Bras. Fisioter. 2010;14(3):237-43.

12. Ciconelli RM, Ferraz MB, Santos W, Meinão I, Quaresma MR. Tradução para a língua portuguesa e validação do questionário genérico de avaliação de qualidade de vida SF-36 (Brasil SF-36). Rev Bras de Reumatol. 1999;39(3):143-50.

13. Melo Neto JS de, Cavalare ADT, Fernando FSL. Qualidade de vida em portadores de hipertensão arterial sistêmica. Ter Man. 2013;11(52):248-51.

14. Zaninelli EM, Graells XSI, Néri OJ, Dau L. Avaliação epidemiológica das fraturas da coluna torácica e lombar de pacientes atendidos no prontosocorro do Hospital do Trabalhador da UFPR de Curitiba - Paraná. Coluna/ Columna. 2005;4(1):11-5.

15. Morais DF, Melo Neto JS de, Spotti AR, Meguins LC, Mussi SE, Tognola WA. Image diagnosis of patients submitted to spinal injury. J Bras Neurocirurg. 2013;24(1):33-9.

16. Bialosky JE, Bishop MD, Price DD, Robinsonc ME, Georgea SZ. The mechanisms of manual therapy in the treatment of musculoskeletal pain: A comprehensive model. Manual Therapy. 2009;14(5):531-8 .

17. Suzuki M, Ohyama N, Yamada K, Kanamori M. The relationship between fear of falling, activities of daily living and quality of life among elderly individuals. Nursing \& Health Sciences. 2002;4(4):155-61.

18. Thuret S, Moon LDF, Gage FH. Therapeutic interventions after spinal cord injury. Nature Reviews Neuroscience. 2006;7:628-43. 